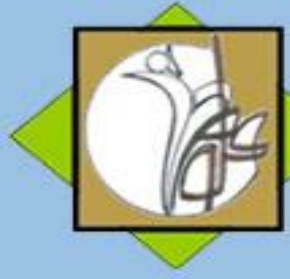

\author{
Research Article
}

\title{
The Effect of Attentional Focus on Gaze Behavior and Accuracy of Dart Throwing: The Attentional Task Demands Problem
}

\author{
Ayoub Asadi ${ }^{1}$, Mahmood Sheikh ${ }^{2}$, Davood Hoomanian ${ }^{3}$, Saleh Rafiei ${ }^{4}$ \\ 1. Ayoub Asadi, (Ph. D) University of Tehran, Tehran, Iran. \\ 2. Mahmood Sheikh, (Ph. D) University of Tehran, Tehran, Iran. \\ 3. Davood Hoomanian, (Ph. D) University of Tehran, Tehran, Iran. \\ 4. Saleh Rafiei, (Ph. D) Sport Sciences Research Institute, Tehran, Iran.
}

\section{ARTICLE INFO}

Received February 2019

Accepted September 2019

\section{KEYWORDS:}

Gaze Behavior,

Focus of Attention,

Load Task, Aiming

\section{CITE:}

Asadi, Sheikh, Hoomanian, Rafiei, The Effect of Attentional Focus on Gaze Behavior and Accuracy of Dart Throwing: The Attentional Task Demands Problem,

Research in Sport Management \& Motor Behavior, 2020: 10(20): 1-16

\section{ABSTRACT}

Focus of Attention and Quiet Eye (QE) of the affecting variables on aiming task performance in recent decades have always been interesting for psychologist and sport science researchers. The purpose of this study was to investigate the effectiveness of attention instructions on gaze behavior and accuracy of dart throwing of novice in low and high task load. In a semi-experimental design with repeated measurements, participant performed dart throwing under three attentional condition (internal, external and control) in two different task load (low and high). Result showed the external focus in high load task improved accuracy of dart throwing than internal focus; in the event that, for low load task there was no significant difference between the attentional conditions. Also, for QE none of attention, load task and their interaction effects was not significant. Results of research for performance supported the constrained action hypothesis; and in contrast to the conscious processing hypothesis. Also the result of gaze behavior suggests several interesting areas for future research. 


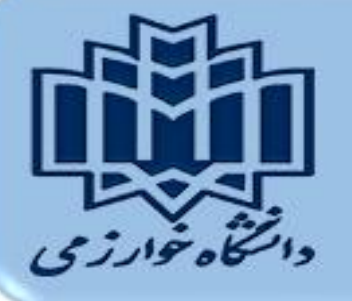

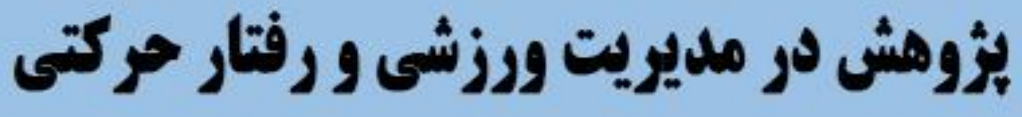

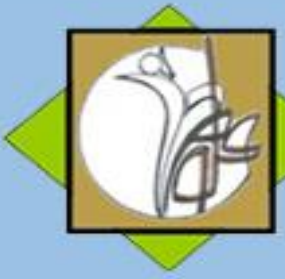

مقاله بثروهشى

\section{تاثير كانون توجه بر رفتار خير گى و دقت يرتاب دارت: مسئله نيازهاى توجهى تكليف}

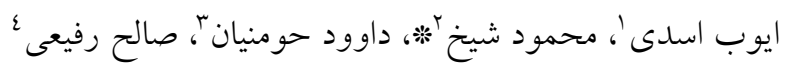

$$
\begin{aligned}
& \text { ا. دانش آموخته دكترى رفتار حركتى، دانشكده تربيت بدنى و علوم ورزشى، دانشكاه تهران، تهران، ايران. } \\
& \text { r. دانشيار كروه رفتار حركتى، دانشكده تربيت بدنى و و علوم ورزشى دونى دانشكاه تهران، تهران، ايران. }
\end{aligned}
$$

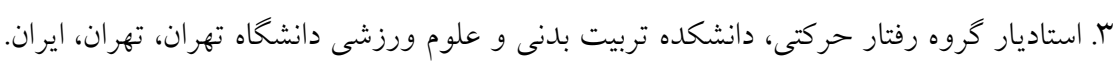

\begin{tabular}{|c|c|}
\hline 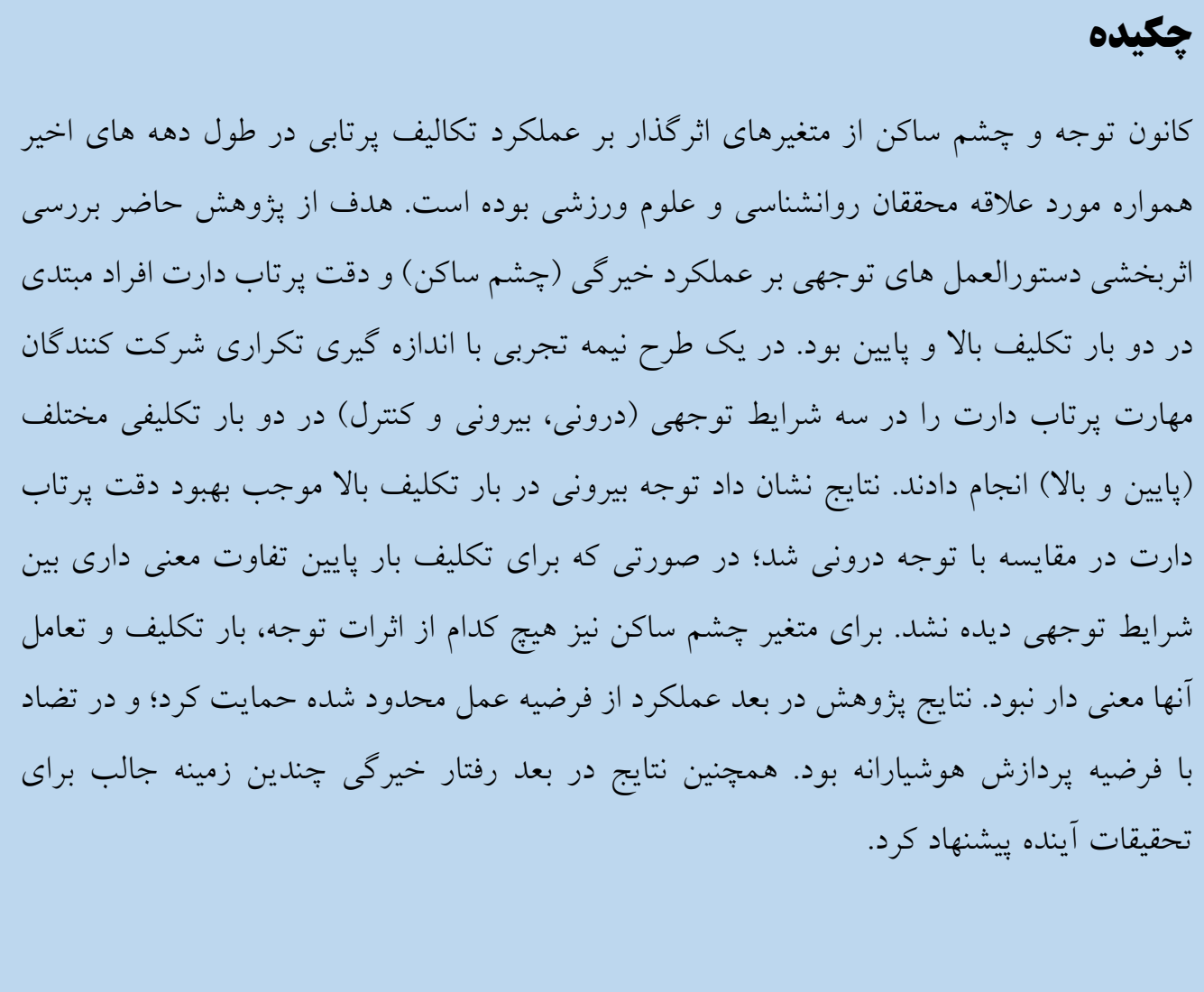 & 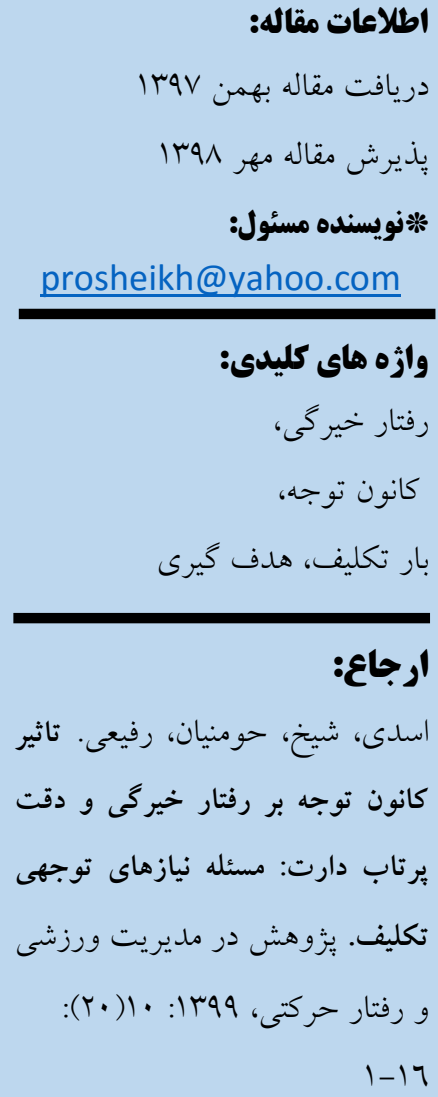 \\
\hline
\end{tabular}

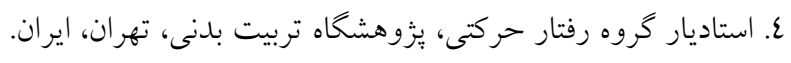




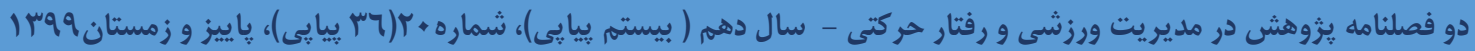

مقلدمه

در طول دهه هاى گذ شته، محققان علوم حركتى همواره اهميت مولفه هاى ادراكى - شناختى براى عملكرد بالا را ذشان داده اند (1). كانون توجه (توجه ينهان) و جֶشم ساكن (توجه آ شكار) به عنوان دو متغير مورد علاقه در اين زمينه مورد يزٔوهش محققان واقع شده است. تحقيقات مختلف نشان داده اند كه كانون توجه عملكرد حركتى را تحت تاثير قرار مى دهد (Y). تحقيقات انجام شــده در اين زمينه به بررسـى ارائه دسـتورالعمل هاى تمركزى به سـوى اثرات حركت (توجه بيرونى) و الكوى حركت (توجه درونى) يرداخته اند. مرور تحقيقات در اين زمينه جٍه در زمينه رفتارى مانند دقت يرتاب

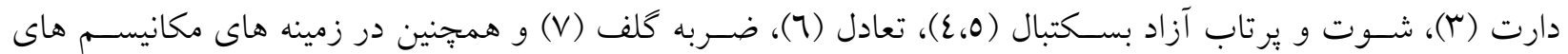
زيربنايى بحركت مثل توليد نيرو بي شينه (9،1)، الكتروان سفالو گرافى و ضربان قلب (•)، فعاليت ء ضلانى كاهش يافته

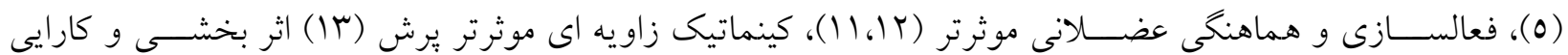
دستور العمل هاى توجه بيرونى را در مقايسه با توجه توجه درونى نشان داده اند. جِشم ساكن يُك ويزّى قوى از تبحر ادراكى است و نمايانحر يك رفتار خاص خيركى قبل از شروع حركت يا يا سخ حركتى است (ع ا-7 (1). به طور خاص جشم ساكن به آخرين ثابت شدن جشم به يك نقطه يا شى خاص در فضاى بينايى حركتى با سه درجه از بينايى مركزى (يا كمتر) براى حداقل · ․ هزارم ثانيه مى باشد (ع)). جُشم ساكن نمايانكر زمان مورد نياز براى سازماندهى شبكه هاى عصسبى و هارامترهاى بينايى مسـئول در جهت دهى و كنترل توجه ديدارى اسـت (ع (). به عبارت ديخر اين متغير بيانكر يك دوره حساس بردازش شناختى است كه طى آن مولفه هاى مربوط يٍاسخ بعدى از قبيل نيرو، جهت و سرعت دقيقا برنامه ريزى و تنظيم شده اند (IV). در تكاليف مختلف ورز شى جّشم ساكن (QE) طولانىتر در افراد ماهر ذ سبت به مبتدى و همجنين عملكرد حركتى موفق نسبت به ناموفق ديله شده است (ع (). دوره بهينه جششم ساكن به هدايت توجه به سـوى هدف و جلو گيرى از حواسـيرتى كمك مى كند (1)). در تكاليف هدفخيرى تحقيقات نشـان داده اند كه علاوه براينكه براى برنامه ريزى بِ سخ مهم ا ست همجنين كنترل قامت را افزايش مى دهد كه براى هدفكيرى بهتر اهميت دارد

همانطور كه در بالا ا شاره شد هردو متغير كانون توجه و جّشم ساكن با عملكرد بهتر در ارتباط هـ ستند. هريك از اين متغيرها تاثيرات مختلفى بر عملكرد حركتى دارد و فر ضيات مختلفى براى تو ضيح اثرات أنها ارائه شده ا ست (ع (Y).

1. Covert Attention

2. Overt Attention

3. Mechanism Underlying

4. Quiet Eye

https://jrsm.khu.ac.ir/ 


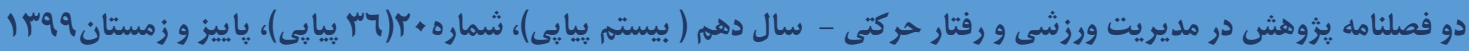

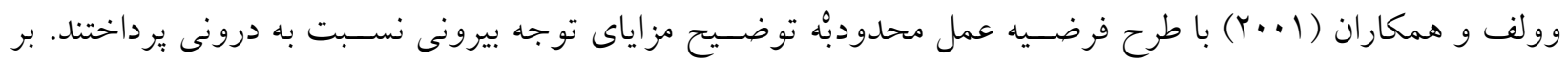
اسـاس اين فرضسيه توجه درونى منجر به كنترل هوشسيارانه حركات و باعث اخلال در اجراى موزون و نرم حركات مى شود در مقابل تمركز بيرونى اجازه كنترل خودكار را به سي ستم حركتى، و به دنبال آن اثربخشى و كارامدى حركات را

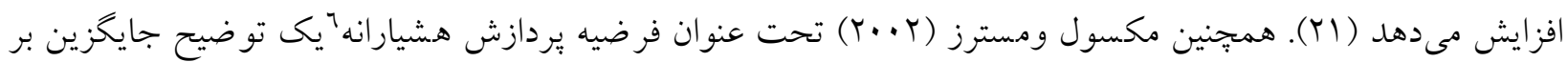
اساس مفاهيم يادكيرى صريح و ضمنى براى عدم برترى توجه بيرونى در شرايط تكليف ثانويه ارائه دادند. آنها استدلال كردند كه توجه بيرونى صرفا يك منبع كه خارج از سي ستم حركتى است درحاليكه در توجه درونى علاوه بر اطلاعات ســــتم حركتى، اطلاعات بيرون سـيسـتم حركتى نيز بردازش مى شـود. در واقع، دسـتور العمل هاى توجه درونى، بار بيشــترى روى منابع توجهى يا حافظه كارى اعمال مى كند (T). در تحقيقات متعدد افزايش بار روى حافظه كارى با عملكرد ضعيف تر مهارت حركتى (Tr) و شكست در هنكام تكليف ثانويهج (Y (Y) مرتبط بوده است. براى توضيح مزاياى

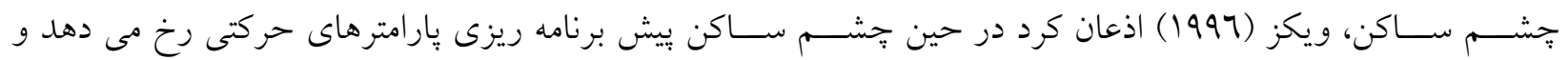
حواسيرتى كاهش مى يابد (Y0). بر اين اساس جشم ساكن بايد از رويداد هاى نامربوط در حين توجه بيرونى جلو گيرى كند (1)). مور وهمكاران (Y (Y) (Y) نيز مطرح كردند كه توجه بيرونى به وسـيله جشــم سـاكن تقويت مى شـود كه ممكن است يكى مكانيسم زيربنايى احتمالى باشد كه جֶشم ساكن عملكرد حركتى را بهبود مى دهد (19). برا ساس اين نتايج، جشم ساكن به عنوان يك مولفه كانون توجه ديدارى بهينه تاكيد شده است (7 (1).

عليرغم برر سى اثربخ شى و كارايى كانون توجه و جِشم ساكن در تحقيقات مختلف، و ارتباط احتمالى اين دو متغير با يكديخر با توجه به اينكه برخى محققين جشّم سـاكن را بخشسى از كانون توجه ديدارى بهينه يا توجه بيرونى مى دانند (19)، آنجه مـ سلم ا ست تعامل اين دو مولفه بر عملكرد حركتى به خوبى مورد برر سى قرار نخرفته است. در تحقيقات انجام شده در اين زمينه در تحقيق رينهوف و همكاران (10 (Y) صرف نظر از شرايط توجه، جخشم ساكن طولانى تر با عملكرد بهتر يرتاب آزاد بسـكتبال در ارتباط بود و جشــم سـاكن در كانون توجه درونى طولانى تر بود (YT)، درحاليكه كلا سترمن و همكاران (عا ·r) مزاياى هر دو متغير كانون توجه و جֶشم ساكن طولانى تر را بر عملكرد ضربه كلف را ذشان دادند، علاوه براين كارايى تجشم ساكنى كه باعملكرد بهتر در ارتباط بود تنها در توجه درونى ديده شد (TV). اما

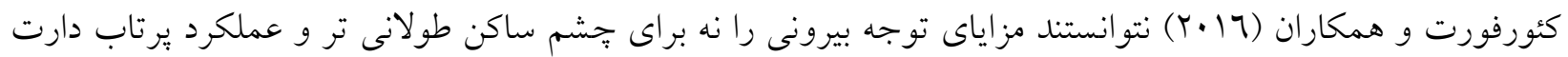
نشــان دهند (YN). يكى از دلايل احتمالى نتايج متناقض اين تحقيقات احتمالا به دليل ماهيت و نيازهاى توجهى متفاوت اين تكاليف باشد. در رابطه با كانون توجه و ماهيت تكليف نشان داده شده است كه در مهارت هايى كه خطا و بى ثباتى

5. Constrained Action Hypothesis 6 . Conscious processing hypothesis 


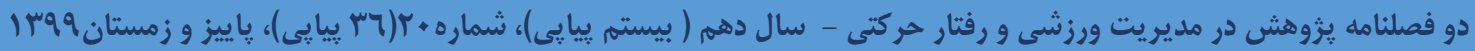

دارند و به عبارت ديخر نياز به يردازش كنترلى بالايى دارند، ارائه توجه بيرونى موجب رهايى اين كنترل آكاهانه شــده و اثربخشى بيشترى به ذسبت مهارت هاى ساده تر دارد (Y9). در زمينه جَشم ساكن نيز كلا سترمن و همكاران (T/ (Y) نشان داد تنها در شرايط بار يردازشى بالا، دوره جِشم ساكن طولانى تر مى تواند براى عملكرد هدفكيرى مفيد مى باشد

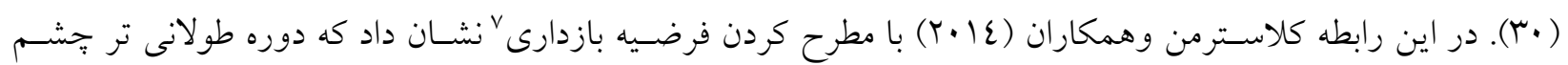
ساكن به و سيله نياز به بازدارى تغييرات حركتى اضافى موجب تغييرات بهينه در حين آماده سازى و همجنين در حين اجراى حركت مى شود. بي شبينى هاى اين فر ضيه بخ صوص در مورد افراد خبره در تكاليف هدفكَىى مورد تاييد قرار كرفته است (YV). بنابراين در تحقيق حاضر به بررسى اثربخشى و كارايى دستور العمل هاى كانون توجه و جُشم ساكن در تكاليف با نيازهاى مختلف يردازشـى برداخته مى شـود و ييشـبينى مى شـود كه كانون توجه بيرونى در شــرايط بار تكليف بالاتر اثربخ شى بي شترى دا شته با شد، همجنين در تكليف با نياز تيرداز شى بالاتر دوره جّ شم ساكن طولانى با عملكرد بهتر در ارتباط خواهد بود. در يايان يكى تعامل بين نوع كانون توجه و دشــوارى تكليف بر عملكرد و جشـــم ساكن بيشبينى مى شود.

\section{روش شناسى}

نوع يُووهش

اين يزوهش از نوع شبه تجربى كاربردى با طرح درون گروهى (اندازه گيرى مكرر) مى باشد.

آزمودنى ها

شركت كنند كان يُزوهش حاضر شامل 17 دانشجوى بِسر رشته علوم ورزشى (دامنه سنى عَ تا .r سال) راست دست بلدون هيج گونه سابقه تمرينى در يرتاب دارت بودند كه به صورت هدفمند انتخاب شدند. تعداد ع نقر از آزمودنى ها به دليل مشكلات تكنيكى مربوط به دستخاه ردياب بينايى نتوانستند آزمون را به بايان بر سانند و از يزوهش حذف شدند و تحقيق در مجموع با זا نفر از آزمودنى انجام شد. اين آزمودنىها هيج كونه مشكلى جسمى و ذهنى نداشتند و صحت سلامت بينايى خود را از طريق خودگزار شى ^به محقق اعلام و با ر ضايت كامل در يزوهش شركت كردند و از اهداف يزووهش بى اطلاع بودند.

7. Inhibition Hypothesis

8. Self-reporting

https://jrsm.khu.ac.ir/ 


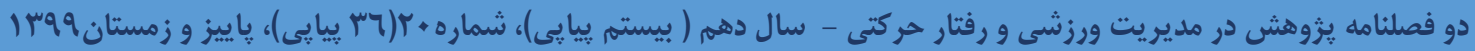

ابزار و تكليف

دقت برتاب دارت: تكليف مورد برر سى در تكليف حا ضر برتاب دارت بود كه در دو شرايط بار تكليف پايين ( صرفا يرتاب دارت) و بار تكليفى بالا (يرتاب دارت همراه تكليف ثانويه فراقامتى) تحت سه شرايط توجه درونى، توجه بيرونى و كنترل انجام شد. تكليف ثانويه نيز شامل يك تكليف كنترل فراقامتى اصلاح شده بهه صورت يكى ورقه مقوايى با ابعاد •ا در •ا سانتى متر بود كه با دست غير برتر انجام شد و شركت كند گان آن را با نوك انخشتان لمس و تلاش كردند آن را در يك حالت ايستاده ثابت حفظ مى كردند (سM-اس). تخته دارت مورد استفاده به شكل دايره و از جنس كاغذ فشرده به قطر سهع و ضخامت كا ميلى متر بود و فاصله و ارتفاع آن بر اساس قوانين اين رشته براى افراد بزرگسال به ترتيب ا و IV/V.

رفتار خيركى: حركات جششم در حين برتاب دارت به و سيله سيستم رديابى بينايى دو خجشمى بيوبيل ( شركت بيوييل، ساخت آلمان) ارزيابى شد. ردياب بينايى با فركانس •7 هزتز (Hz) به يك لبتاب (شركت إبل، ساخت آمريكا) به وسيله كابل يو اس بى و صل و ويدئو ضبط شده تو سط ردياب بينايى در آن ذخيره مى شد. اين د ستخاه حركات دو جششم را

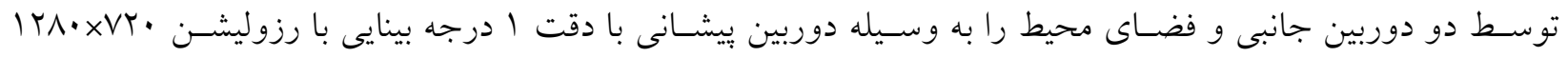

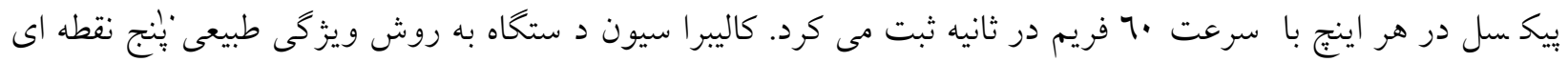
روى صفحه دارت در موقعيت مشابه يرتاب دارت توسط شركت كننده و آزمونخر انجام شد. علاوه براين از يك دوربين فيلم بردارى جانبى سونى با سرعت •7 فريم در ثانيه در سمت راست شركت كنندكان قرار داشت كه حركات يرتاب دارت شـركت كنند گان را در سـطح سـاجيتال 'طــبط مى كرد. قبل از هر كوشـش يكى نور ليزر ارائه مى شـد كه توسـط دوربين جانبى و دوربين ردياب بينايى ثبت مى شـــ. اين نور به عنوان يك رفرنس براى همزمان سـازى گّو ويدئو براى تحليل هاى بعدى استفاده شد. اطلاعات ويدئويى حاصل از ردياب بينايى به صورت فريم به فريم با استفاده از نرم افزار

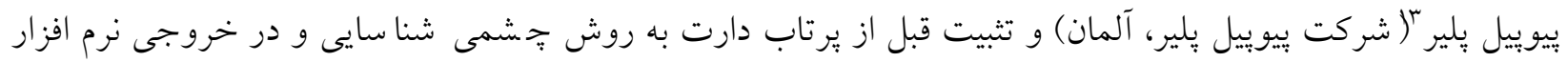
اكسل مشخص و ثبت شد. هر دو ويدوئو حاصل از ردياب بينايى و دوربين جانبى با استفاده از رويداد نورى از طريق نرم افزار كينويا (Kinovea 0.8.15 for Windows; available at http://www.kinovea.org همزمان سـازى شـــ اين روش اجازه يك همزمان سازى دقيق اطلاعات خيركى و داده هاى حركتى را فراهم مى كرد.

9 Modified supra-postural control task

10 .Natural Features

11 .Sagittal Plane

12 .Synchronization

13 .Pupil Player

https://jrsm.khu.ac.ir/ 


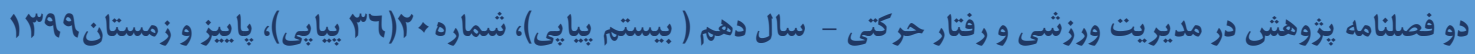

\section{روش اجرا}

پِ از انتخاب شركت كنندكان و كرفتن ر ضايت، از آنها در خوا ست شد كه در مقابل دارت بايد ستند و از نحوه انجام

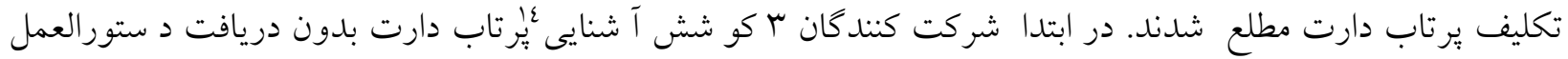
توجهى و ثبت نتيجه انجام دادند. شـركت كنند كان در شـرايط بار تكليف كم صـرفا برتاب دارت را تحت سـه شـرايط آزمايشى كتترل، درونى و بيرونى انجام دادند. دستورالعمل ها مورد استفاده در تحقيق حاضر بر اساس تحقيقات بيشين

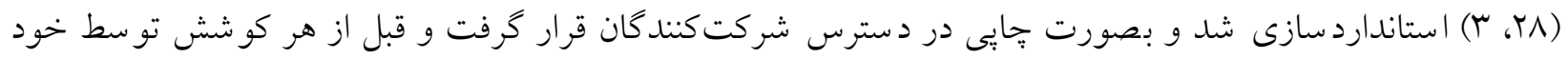
آنها يا آزمونكر قرائت مى شد. در همه شرايط آزمايشى از آزمودنى درخواست شد كه تا يرتاب دارت را با حداكثر دقت انجام دهل با اين تفاوت كه در شــايط توجه درونى دسـتور العمل "تمركز روى حركات دسـت برتاب" و در شـرايط توجهى بيرونى د ستورالعمل "تمركز روى مـ سير يرواز دارت به سمت صفحه دارت" داده شد، ولى در شرايط كنترل هيج گونه دستور العمل توجهى داده نشد.

براى تكليف دو گانه نيز آزمودنى ها تكليف يرتاب دارت همراه تكليف كنترل فراقامتى را تحت سـه شــرايط آزمايشـى كنترل، درونى و بيرونى انجام دادند. در سه شرايط كفته شده از آزمودنى درخواست شد كه هر دو تكليف يرتاب دارت و فراقامتى را حداكثر دقت انجام دهند با اين تفاوت كه در شـــايط توجه درونى دســتور العمل " تمركز روى حركات د ست برتاب " و در شرايط توجه بيرونى د ستورالعمل " تمركز روى مـسير برواز دارت به سمت صفحه دارت " داده شد. در شرايط كنترل نيز هيج كونه د ستورالعمل توجهى داده ذشد. لازم به ذكر است كه نيمى از شركت كنند كان ابتدا تكليف بار كم و سبس تكليف بار زياد را انجام دادند و نصف ديكر ابتدا تكليف بار زياد و سبس تكليف بار كم را انجام دادند و براى جلو گيرى از اثر ترتيب نيز در هر كدام از تكاليف كليه شركت كنندگان ابتدا در شرايط كنترل قرار كرفته و

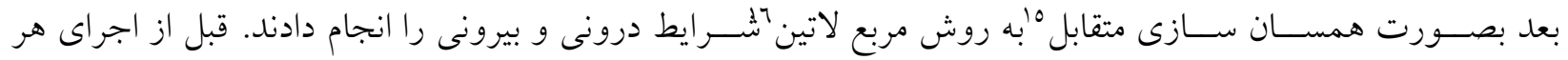
كوشش، شركتكنند گان دستورالعمل توجهى مرتبط با شرايط خود را كه بر روى برگه اى نوشته شده بود با صداى بلند باز گو كردند، اين كار براى تاثير گذارى هرجهه بيشتر دستور العمل هاى توجهى انجام شد. لازم به ذكر است بعد از هر سه كوشـش يرتاب دارت و ثبت همزمان اطلاعات خيركى به صــورت خودكار، آزمونخر دارت ها را بازيابى و امتياز آن را

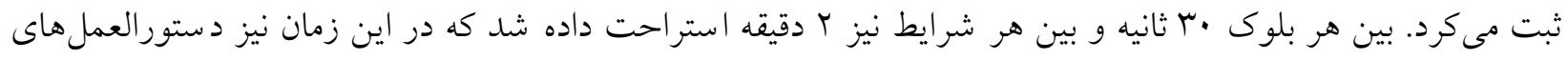

14 .Familiarization

15 .Counterbalance

16 .Latin Square

https://jrsm.khu.ac.ir/ 


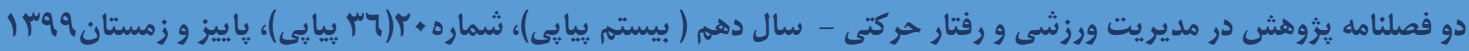

توجهى ارائه و صحت كاليبريشن بررسى شد. تعداد كوشش هاى انجام شده در هر كدام از شرايط شرايط \ل يرتاب در قالب 7 بلوى ץ كوششى بود، در مجموع هريك از آزمودنى ها در شش شرايط آزمايشى 1 •ا يرتاب دارت انجام دادند.

\section{روش آمارى}

از آمار تو صيفى براى طبقهبندى و تنظيم دادهها و تعيين شاخص مركزى (ميانخين) و شاخص بر اكندگى (انحراف معيار) و ترسيم نمودارها و جداول مختلف در شرايط مختلف استفاده شد. در بخش استنباطى نرمال بودن توزيع اندازه كيرى با آزمون شــاييرو -ويلك مورد بررسـى قرار گرفت. براى تجزيه و تحليل فرضــيه ها نيز از تحليل واريانس عاملى توجه (كنترل، درونى، بيرونى) در بار تكليف (كم و زياد) با اندازه كيرى مكرر روى عامل ها اســتفاده شــــ. تحليل دادهها با

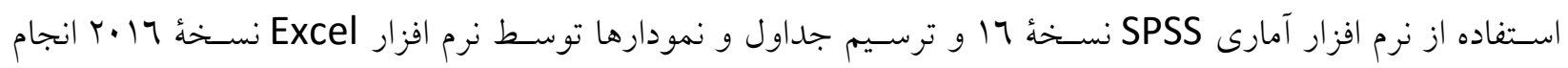
كرفت. كليه عمليات آمارى در سطح معنى دارى 0 •/ $0=$

\section{نتايج}

همانطور كه در بالا اشاره شد در تحقيق حاضر صرفا عملكرد حركتى (شكل I) و خيرگى (شكل r) در مهارت يرتاب دارت مورد ارزيابى قرار گرفت و هيج گونه اندازه گيرى روى تكليف ثانويه انجام نشد و اين تكليف صرفا جهت اعمال بار تكليف اعمال شده بود.

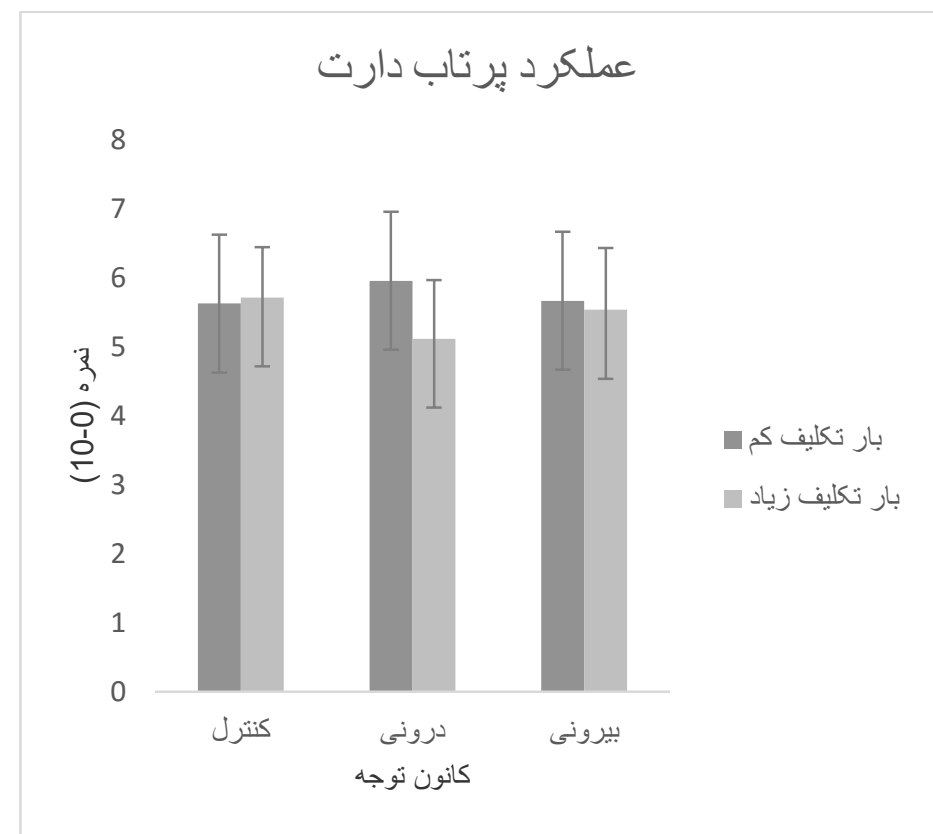

شكل 1. عملكرد يرتاب دارت تحت شرايط كانون توجه در دو بار تكليف كم و زياد

https://jrsm.khu.ac.ir/ 


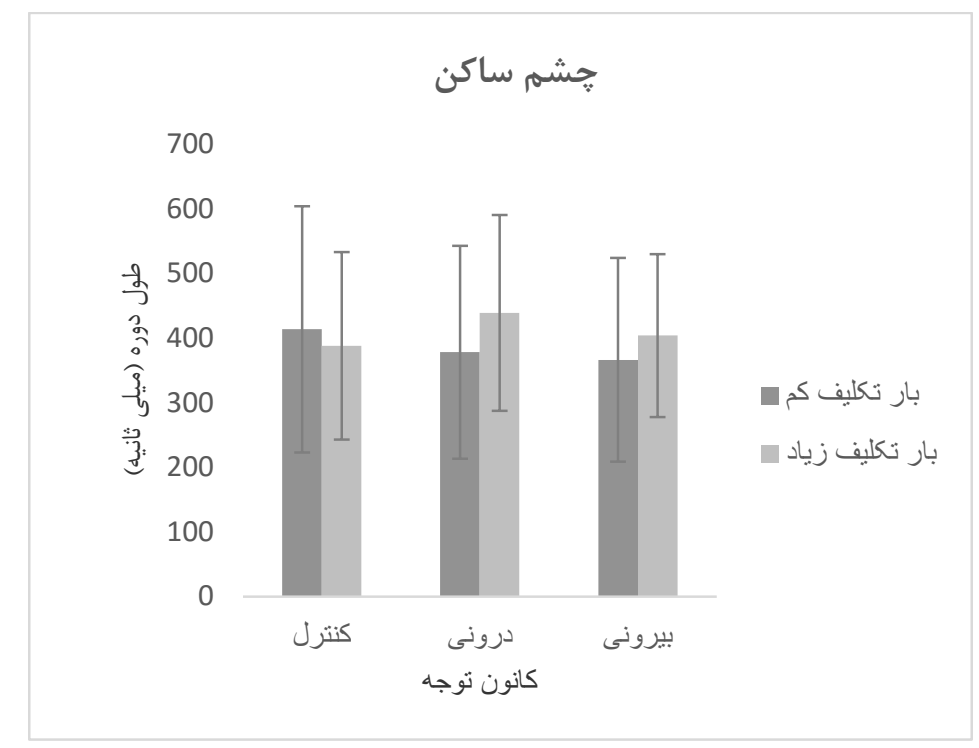

شكل r. مدت زمان جشم ساكن برتاب دارت تحت شرايط كانون توجه در دو بار تكليف كم و زياد

در ابتدا تجزيه و تحليل نتايج يزوهش طبيعى بودن توزيع داده ها با اسـتفاده از آزمون شـاييرو ويلك مورد بررسسى قرار كرفت كه نتايج آن نشان داد توزيع داده هاى بدست آمده نرمال مى باشد (P>0.05). جدول ا. نتايج تحليل واريانس عاملى ץ بار تكليف (كم، زياد) در با توجه (بيرونى، درونى، كترل) بر عملكرد و جشم ساكن در يرتاب دارت

\begin{tabular}{|c|c|c|c|c|c|c|}
\hline اندازه اثر & معنادارى سطح & $\mathbf{F}$ & درجه آزادى & آزادى & منابع تغييرات & \\
\hline$/ . r$ & $\cdot / N$ & $\cdot / \mu$ & r & r & اثر توجه & \multirow{3}{*}{ عملكرد } \\
\hline.$/ I V$ & .110 & $r / T V$ & 11 & 1 & اثر تكليف & \\
\hline$\cdot / T \Lambda$ & $* \cdot / \cdot r$ & $\varepsilon / \pi \varepsilon$ & r & r & اثر تعاملى توجه و تكليف & \\
\hline$\cdot / \cdot \varepsilon$ & $\cdot / 7 r$ & $\cdot / \varepsilon V$ & rt & r & اثر توجه & \multirow{3}{*}{ ساكن } \\
\hline$\cdot / \cdot V$ & $\cdot r V$ & $\cdot / 17$ & 11 & 1 & اثر تكليف & \\
\hline$\cdot / T 1$ & $\cdot / \cdot v$ & $r / 90$ & Tr & r & اثر تعاملى توجه و تكليف & \\
\hline
\end{tabular}




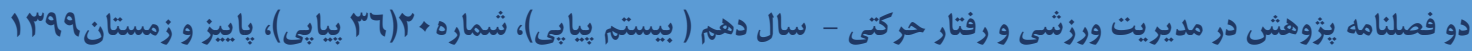

نتايج تحليل واريانس عاملى با فرض كرويت موخلى (P>0.05) براى عملكرد نشـان داد كه اثر اصـلى توجه و تكليف معنى دار نمى با شد ولى اثر تعاملى توجه و تكليف معنى دار ا ست. براى متغير خجشم ساكن، هيج كدام از اثرات توجه، تكليف و تعاملى معنى دار نبود (جدول (). با توجه به معنى دار شـــن اثر تعاملى توجه و تكليف در عملكرد ، بيخيرى نتايج با تعديل سطح معنى دارى با استفاده از دو آزمون تحليل واريانس درونكروهى و سه آزمون تى همبسته براى تاثير و تفاوت كانون توجه در تكاليف باركم و بار زياد مورد بررسى قرار كرفت.

جدول r. نتايج آزمون تحليل واريانس درونگروهى براى تاثير شرايط توجهى بر عملكرد برتاب دارت در دو شرايط بار تكليف بالا و بايين

\begin{tabular}{|c|c|c|c|c|c|c|}
\hline اندازه اثر & معنادارى سطح & $\mathbf{F}$ & درجه آزادى & آز آزادى & منابع تغييرات & \\
\hline .1 .9 & • & $1 / / V$ & rt & r & اثر كانون توجه در بار تكليف & \multirow[t]{2}{*}{ عملكرد } \\
\hline$\cdot / Y 7$ & $* \cdot / \cdot r$ & $r / 9 r$ & rr & r & اثر كانون توجه در بار تكليف بالا & \\
\hline
\end{tabular}

با فرض كرويت موخلى (P>0.05) نتايج آزمون تحليل واريانس با اندازه كيرى مكرر با تعديل آلفا (PS0/025) ذ شان داد كه اثر اصلى كانون توجه در شرايط تكليف بار كم معنى دار نبود، اما اين اثر در تكليف بار بالا معنى دار بود (جدول r). براى ديدن تفاوت هاى بين شــرايط از آزمون تعقيبى بونفرونى اسـتفاده گرديد كه نتايج آن در جدول با آورده شـده

جدول س. نتايج آزمون تعقيبى بونفرونى براى ديدن تفاوت هاى بين شرايط توجهى در بار تكليف بالا

\begin{tabular}{|c|c|c|c|}
\hline معنى دارى & اختلاف ميانگين & شرايط (j) & شرايط (i) \\
\hline$* / \cdot r$ & $\cdot / 7$ & توجه درونى & \multirow{2}{*}{ كنترل } \\
\hline$\cdot / 0 r$ & $\cdot / I V$ & توجه بيرونى & \\
\hline$* / \cdot 1$ & $-\bullet / \varepsilon r$ & توجه بيرونى & توجه درونى \\
\hline
\end{tabular}

نتايج آزمون تعقيبى بونفرونى در بار تكليف بالا نشان داد كه افراد در دو شرايط توجه بيرونى و كنترل به طور معنى دارى عملكرد بهترى ذسبت به شر ايط توجه درونى داشتند، ولى بين شرايط توجه بيرونى و كنترل تفاوت معنى دارى مشاهده نشد (جدول، r). 


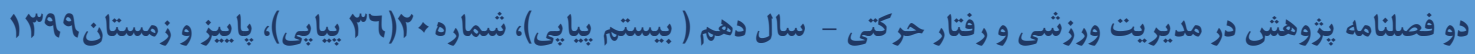

جدول ع. نتايج آزمون t همبسته براى ديدن تفاوت هاى شرايط توجه در بار تكليف بالا و پايين

\begin{tabular}{|c|c|c|c|c|}
\hline معنى دارى & اختلاف ميانخين & بار تكليف (j) & بار تكليف (i) & شرايط \\
\hline . /vo & $-\cdot / \cdot 1$ & بالا & بإيين & كنترل \\
\hline$* / \cdots r$ & $-\cdot / \wedge \varepsilon$ & بالا & بايين & توجه درونى \\
\hline$\cdot / v$ &.$/ 1 T$ & بالا & بإيين & توجه بيرونى \\
\hline
\end{tabular}

نتايج آزمون t همبسته با تعديل آلفا (PSO/016) نشان داد كه افراد در توجه درونى بار تكليف بالا نسبت شرايط توجه درونى در بار تكليف پِيين عملكرد ضعيف ترى در يرتاب دارت دا شتند. اما براى توجه بيرونى و كنترل بين بار تكليف بالا و پِيnن تفاوت معنى دارى وجود نداشت (جدول، ع).

\section{بحث و نتيجه}

اولين هدف يزوهش حا ضر برر سى اثربخ شى كانون توجه بر دقت برتاب دارت افراد مبتدى در دو بار تكليفى متفاوت بود. نتايج حاكى از آن بود كه اتخاذ كانون توجه بيرونى در شــرايط بار تكليفى بالا (تكليف دارت همراه تكليف ثانويه فراقامتى) موجب ارتقاى عملكرد يرتاب دارت افراد مبتدى در مقايسه با توجه درونى مى شود؛ در حاليكه در شرايط بار تكليفى يايين (صرفا يرتاب دارت) بين اثربخشى كانون توجه بيرونى و درونى تفاوت معنى دارى ديده نشد. تعداد زيادى از مطالعات در زمينه كانون توجه نشـان داده شـده توجه بيرونى نسـبت به توجه درونى مزاياى بيشـترى دارد (Y). اما بر خلاف تحقيقات ييشـين در شـرايط بار تكليفى كم نتواسـيم تفاوتى در عملكرد يرتاب دارت را با توجه به اتخاذ كانون

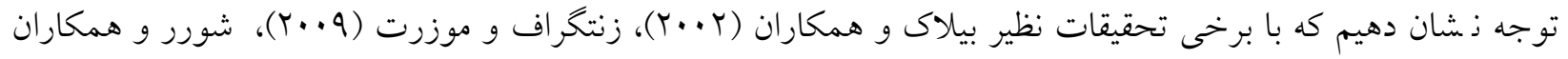

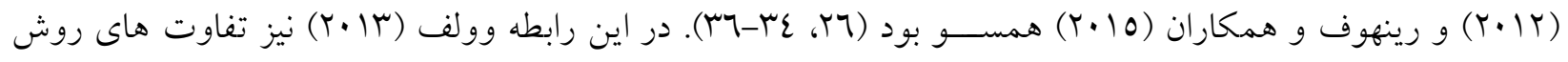
شناختى را علت تناقض تحقيقات ناهمسو با اكثريت تحقيقات كه اثربخشى كانون توجه را ذشان داده اند ذكر كرده بود (Y). اما بر خلاف شــرايط بار تكليفى بايين، در بار تكليفى بالا اتخاذ كانون توجه بيرونى نسـبت به توجه درونى مزاياى بيشترى براى عملكرد برتاب دارت افراد داشت. شواهدى وجود دارد كه اجرا تحت بار تكليف ثانويه در اثر محدوديت در حافظه كارى و توجه ضعيف مى شود (YVIVI). آنجهه در آزمون هاى تعقيبى اثر تعاملى مـ شهود بود افت اجرا تحت تكليف ثانويه در شرايط توجه درونى بسيار بيشتر از توجه بيرونى بود. به نظر مى رسد شكست اجرا تحت شرايط توجه درونى در تكليف دو گانه به دليل بكارگيرى حافظه كارى و يردازش آشــكار مى باشــــ (YV). به بيان ديخر اتخاذ كانون توجه درونى نسـبت به توجه بيرونى در تكليف دو گانه بار مضـاعفى را بر سـيسـتم حركتى اعمال مى كند. به طور كلى 


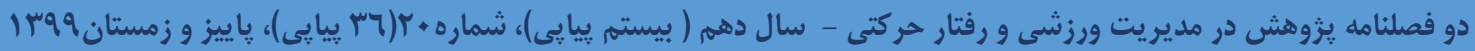

دستورالعمل هاى توجه درونى به دليل استفاده قوانين صريح يا آشكار و كنترل هوشيارانه حركت مى شوند (ع). نتيجه جالب ديكر تحقيق حاضر عدم كاهش اجرا در شرايط توجه بيرونى در بار تكليفى بالا نسبت به شرايط توجه بيرونى در

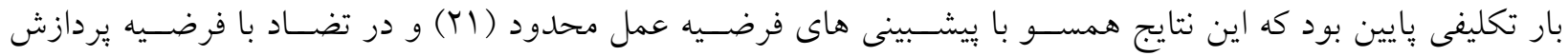
هشـيارانه (Yr) بود. بر اسـاس فرضـيه عمل محدود اجرا در شـرايط توجه بيرونى در شـرايط بار تكليف ثانويه به دليل افزايش ساز كارى اطلاعات با برنامه ريزى و عمل بايد همجنان استوار بماند (Y). اما بيشبينى فرضيه يردازش هشيارانه بدين صورت است كه در شرايطى كه بار اضافه نظير تكليف ثانويه بر سيستم حركتى اعمال شود، در هر دو شرايط توجه بيرونى و درونى نسبت به شرايط تكليف يك گانه عملكرد ضعيف تر مى شود (rV). با توجه به نتايج يزوهش حاضر به نظر مى رسد دستورالعمل هاى توجه بيرونى در شرايط بار شناختى بالاتر نسبت به بار شناختى كمتر اثربخشى بيشترى براى عملكرد حركتى دارند.

دومين هدف يزوهش بررسى متغير جشّم سـاكن تحت شـرايط مختلف توجهى در دو بار مختلف تكليف بود كه هيج كدام از اثرات توجه، بار تكليف و تعامل اين دو از نظر آمارى معنى دار نبود. همجنين با بررسـى اطلاعات مربوط به عملكرد و خير گى ذشان داده شد عملكرد بهتر برتاب دارت با طول دوره طولانى تر جششم ساكن مرتبط نبود. تحقيقات نشـان داده اند كه نوع بردازش اطلاعاتى كه رخ مى دهد و اطلاعات مورد اسـتفاده در دوره جششـم سـاكن مى تواند بر اساس تكنيك هاى مختلف اجراى مهارت متفاوت باشد (YN) كه مى تواند اثربخش بودن دوره جّشم ساكن بر عملكرد

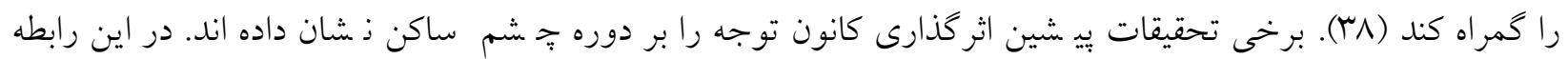
جشـم سـاكن طولانى تر تحت تاثير توجه درونى (YT) يا كارايى جشـم سـاكن در توجه درونى (YV) نشـان داده شـــ. كلاسترمن و همكاران (ع) (Y) با حمايت از فر ضيه بازدارى مطرح كردند كه توجه درونى موجب تقاضاى مهارى بيشتر ذسبت به توجه بيرونى مى شود (YV). نتايج حاضر در بعد اثركذارى دوره جِشم ساكن بر عملكرد حركتى از بي شبينى هاى فر ضيه بازدارى حمايت نكرد. در تحقيقات بيشين نشان داده شد افراد خبره دوره جّشم ساكن طولانى ترى نسبت به افراد مبتدى دارند و بخصوص براى افراد خبره دوره طولانى تر خشمم ساكن با عملكرد بهتر ارتباط دارد (YO). با اين

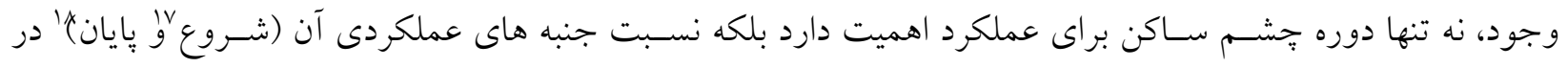

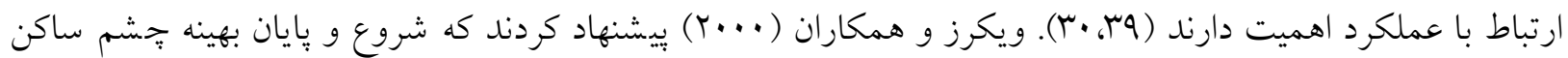

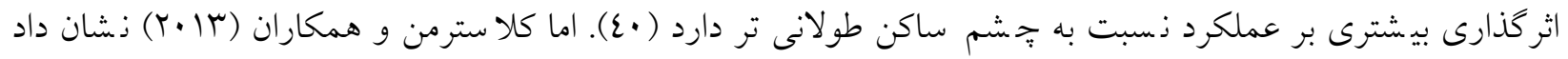




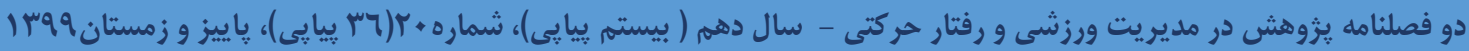

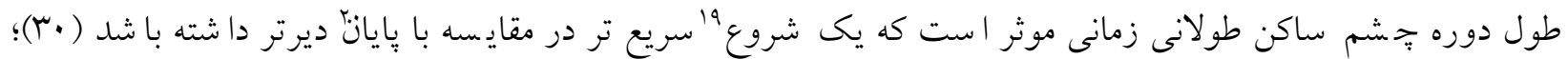
بدين معنى كه در يك جشم ساكن معين زمانى كه بخش بايانى طولانى تر از شروع باشد تاثير كذارى بيشترى بر عملكرد

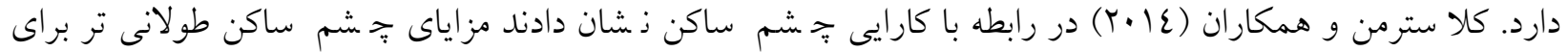
عملكرد بهتر تنها در افراد ماهر و در شرايط توجه درونى ديده شد. جنين به نظر مى ر سد كه فر ضيه بازدارى مى تواند اثربخشى دوره جشم ساكن بر عملكرد حركتى را بيشتر در افراد ماهر نسبت به افراد مبتدى نشان دهد (TV)؛ و اثربخشى آن در افراد غير ماهر نظير تحقيق حاضر به اندازه افراد ماهر نيست.

اين يزوهش نيز همانند تحقيقات بيشــين نيمه تجربى داراى محدوديت هايى بود كه در تحقيقات آينده بايسـتى اين محدوديت ها در نظر گرفته شــود و اين تحقيق را به عنوان يك مطالعه مفيد مقدماتى در نظر گرفته شــود. بنابراين در تحقيقات آينده لازم اسـت به بررسى دسـور العمل هاى كانون توجه يُرداخته شـود؛ همجنين ديخر شـرايط اتخاذ توجه. بيرونى براى تعيين اينكه كدام نشـــانه هاى بيرونى مانند فواصـلـل مختلف (دور و نزديك) و منابع مختلف (مربوط و نامربوط به تكليف) به عنوان توجه بيرونى اثربخش تر اسـت در نظر كرفته شـود. براى درك عميق تر از مكانيسـم هاى اصلى كانون توجه به برر سى زمانبندى (شروع و پِايان) متغير خششم ساكن در سطوح مختلف تبحر و دوره هاى سنى مورد بررسى قرار كيرد.

نتيجه گيرى كلى حاصل از تحقيق حاضر حاكى از آن است كه در شرايط بار و درگيرى بيشتر حافظه كارى و سيستم حركتى اتخاذ كانون توجه بيرونى موجب بهبود عملكرد حركتى افراد مبتدى مى شود. بنابراين مى توان اطلاعات مفيدى به مربيان و ورز شكاران ارائه دهد بدين صورت كه ارائه دستورالعمل هاى هايى كه توجه آزمودنى را جنبه هاى محيطى حتى در شرايط تكليف ثانويه موجب بهينه سازى كتترل حركت بر اساس نتايج محيطى يا اثرات حركت مى شود. 
1. Mann DT, Williams AM, Ward P, Janelle CM. Perceptual-cognitive expertise in sport: A meta-analysis. Journal of Sport and Exercise Psychology. 2007 Aug 1;29(4):457-78.

2. Wulf G. Attentional focus and motor learning: a review of 15 years. International Review of sport and Exercise psychology. 2013 Sep 1;6(1):77-104.

3. Lohse KR, Sherwood DE, Healy AF. How changing the focus of attention affects performance, kinematics, and electromyography in dart throwing. Human Movement Science. 2010 Aug 1;29(4):542-55.

4. Saemi, E., Abdoli, B., Farsi, A., \& Sanjari, M. The Effect of Differential Attentional Focus Strategies on Accuracy of Free Throw in Novice Basketball Throwers: The Role of Visual Information. Journal of Sport Psychology Studies. (2016). 4(14): 112-99. (in Persian)

5. Zachry T, Wulf G, Mercer J, Bezodis N. Increased movement accuracy and reduced EMG activity as the result of adopting an external focus of attention. Brain research bulletin. 2005 Oct 30;67(4):304-9.

6. Chiviacowsky S, Wulf G, Wally R. An external focus of attention enhances balance learning in older adults. Gait \& posture. 2010 Oct 1;32(4):572-5.

7. Bell JJ, Hardy J. Effects of attentional focus on skilled performance in golf. Journal of Applied Sport Psychology. 2009 May 6;21(2):163-77.

8. Wulf G, Dufek JS, Lozano L, Pettigrew C. Increased jump height and reduced EMG activity with an external focus. Human movement science. 2010 Jun 1;29(3):440-8.

9. Wulf G, Zachry T, Granados C, Dufek JS. Increases in jump-and-reach height through an external focus of attention. International Journal of Sports Science \& Coaching. 2007 Sep;2(3):275-84.

10. Radlo, S. J., Steinberg, G. M., Singer, R. N., Barba, D. A., \& Melnikov, A. The influence of an attentional focus strategy on alpha brain wave activity, heart rate and dart-throwing performance. International Journal of Sport Psychology. (2002). 33(2), 205-217.

11. Lohse KR, Sherwood DE. Thinking about muscles: The neuromuscular effects of attentional focus on accuracy and fatigue. Acta psychologica. 2012 Jul 1;140(3):236-45.

12. Lohse KR, Sherwood DE, Healy AF. Neuromuscular effects of shifting the focus of attention in a simple force production task. Journal of Motor Behavior. 2011 Feb 28;43(2):173-84.

13. Asadi A, Farsi A, Abdoli B, Saemi E, Porter JM. Directing Attention Externally and Self-Controlled Practice Have Similar Effects on Motor Skill Performance. Journal of Motor Learning and Development. 2019 Apr 1;7(1):141-51.

14. Vickers JN. The quiet eye: Origins, controversies, and future directions. Kinesiology Review. 2016 Apr 20;5(2):119-28.

15. Vickers JN. Perception, cognition, and decision training: The quiet eye in action. Human Kinetics; 2007.

https://jrsm.khu.ac.ir/ 
16. Vine SJ, Moore LJ, Wilson MR. Quiet eye training: The acquisition, refinement and resilient performance of targeting skills. European journal of sport science. 2014 Jan 1;14(sup1):S235-42.

17. Williams AM, Singer RN, Frehlich SG. Quiet eye duration, expertise, and task complexity in near and far aiming tasks. Journal of Motor Behavior. 2002 Jun 1;34(2):197-207.

18. Wilson MR, Pearcy RC. Visuomotor control of straight and breaking golf putts. Perceptual and Motor Skills. 2009 Oct;109(2):555-62.

19. Moore LJ, Vine SJ, Cooke A, Ring C, Wilson MR. Quiet eye training expedites motor learning and aids performance under heightened anxiety: The roles of response programming and external attention. Psychophysiology. 2012 Jul;49(7):1005-15.

20. Vine SJ, Wilson MR. The influence of quiet eye training and pressure on attention and visuo-motor control. Acta psychologica. 2011 Mar 1;136(3):340-6.

21. Wulf G, McNevin N, Shea CH. The automaticity of complex motor skill learning as a function of attentional focus. The Quarterly Journal of Experimental Psychology Section A. 2001 Nov;54(4):1143-54.

22. Maxwell JP, Masters RS. External versus internal focus instructions: Is the learner paying attention? International Journal of Applied Sports Sciences. 2002 Dec 1;14(2):70-88.

23. Maxwell JP, Masters RS, Eves FF. From novice to no know-how: A longitudinal study of implicit motor learning. Journal of sports sciences. 2000 Jan 1;18(2):111-20.

24. Maxwell JP, Masters RS, Eves FF. The role of working memory in motor learning and performance. Consciousness and cognition. 2003 Sep 1;12(3):376-402.

25. Vickers JN. Visual control when aiming at a far target. Journal of Experimental Psychology: Human perception and performance. 1996 Apr;22(2):342-352.

26. Rienhoff R, Fischer L, Strauss B, Baker J, Schorer J. Focus of attention influences quiet-eye behavior: An exploratory investigation of different skill levels in female basketball players. Sport, Exercise, and Performance Psychology. 2015 Feb;4(1):62-74.

27. Klostermann A, Kredel R, Hossner EJ. On the interaction of attentional focus and gaze: the quiet eye inhibits focus-related performance decrements. Journal of Sport and Exercise Psychology. 2014 Aug 1;36(4):392-400.

28. Querfurth S, Schücker L, de Lussanet MH, Zentgraf K. An internal focus leads to longer quiet eye durations in novice dart players. Frontiers in psychology. 2016 May 2;7:633. doi: 10.3389/fpsyg.2016.00633.

29. Wulf G, Töllner T, Shea CH. Attentional focus effects as a function of task difficulty. Research quarterly for exercise and sport. 2007 Jun 1;78(3):257-64.

30. Klostermann A, Kredel R, Hossner EJ. The "quiet eye" and motor performance: Task demands matter! Journal of Experimental Psychology: Human Perception and Performance. 2013 Oct;39(5):1270-78.

31. Riley MA, Stoffregen TA, Grocki MJ, Turvey MT. Postural stabilization for the control of touching. Human Movement Science. 1999 Dec 1;18(6):795-817. 
32. McNevin NH, Wulf G. Attentional focus on supra-postural tasks affects postural control. Human movement science. 2002 Jul 1;21(2):187-202.

33. Russell R, Porter J, Campbell O. An external skill focus is necessary to enhance performance. Journal of Motor Learning and Development. 2014 Jun 1;2(2):37-46.

34. Beilock SL, Carr TH, MacMahon C, Starkes JL. When paying attention becomes counterproductive: impact of divided versus skill-focused attention on novice and experienced performance of sensorimotor skills. Journal of Experimental Psychology: Applied. 2002 Mar;8(1):6-16.

35. Zentgraf K, Munzert J. Effects of attentional-focus instructions on movement kinematics. Psychology of Sport and Exercise. 2009 Sep 1;10(5):520-5.

36. Schorer J, Jaitner T, Wollny R, Fath F, Baker J. Influence of varying focus of attention conditions on dart throwing performance in experts and novices. Experimental brain research. 2012 Mar 1;217(2):28797.

37. Poolton JM, Maxwell JP, Masters RS, Raab M. Benefits of an external focus of attention: Common coding or conscious processing?. Journal of sports sciences. 2006 Jan 1;24(1):89-99.

38. De Oliveira RF, Oudejans RR, Beek PJ. Gaze behavior in basketball shooting: Further evidence for online visual control. Research quarterly for exercise and sport. 2008 Sep 1;79(3):399-404.

39. De Oliveira RF, Oudejans RR, Beek PJ. Late information pick-up is preferred in basketball jump shooting. Journal of Sports Sciences. 2006 Sep 1;24(9):933-40.

40. Vickers JN, Rodrigues ST, Edworthy G. Quiet eye and accuracy in the dart throw. International Journal of Sports Vision. 2000;6(1):30-6. 